\title{
Analysis on galloping models of iced transmission lines
}

\author{
You Yi 1,a, Yan Zhi-tao 2,b, Wang Ling-zhi²,c, Li Peng ${ }^{2, d}$ \\ ${ }^{1}$ State Grid Xinjiang Electric Power Company Electric Power Research Institute, Urumqi, China, \\ 830011; \\ ${ }^{2}$ School of Civil Engineering, Chongqing University of Science \& technology, Chongqing, China, \\ 401331; \\ a97080463@qq.com, byanzhitaoz@cqu.edu.cn, c20121602076t@cqu.edu.cn, \\ d740658984@qq.com.
}

Keywords: curved beam theory, iced transmission lines, galloping, boundary stiffness, boundary mass

Abstract: Based on the cable theory and the curved beam theory, the 3-DOF galloping model of iced transmission lines was established. According to the Hamilton principle, the three-freedom galloping models based on cable theory, based on the curved beam theory, based on the curved beam theory considering the boundary stiffness and galloping models based on the curved beam theory with both the boundary stiffness and boundary mass considered were developed utilizing the Mathematica procedure. The results show that the data obtained by the galloping model based on the curved beam theory with the adjacent stiffness and the insulator string mass taken into account are consistent basically with the test results.

\section{Introduction}

The galloping of the transmission lines will cause great damage to the power transmission system.

Various galloping models of iced transmission lines were established by scholars from all over the world. In the 1930s, Den.Hartog[1], Kazakevich[2] and Nigol[3-4] proposed the theoretical model of vertical galloping theory and torsion galloping theory of single degree of freedom. Then Jones[5] and Luongo[6] presented a 2-degree-freedom (2-DOF) galloping model considering both vertical and horizontal components, but the model did not consider the effect of torsion on galloping. Then Blevins[7] and Dessai[8] established a 2-DOF galloping model considering torsional and vertical components. Finally, a 3-DOF galloping model taking into account the vertical component, the horizontal component and the torsional component, as well as considering the boundary conditions such as the adjacent equivalent stiffness and the insulator string was proposed by $\mathrm{P}$. Yu[9]. The influence of eccentricity of cross section of iced conductor was considered. However, all the above models are established based on the cable theory, ignoring the bending stiffness of the structure.

In order to discuss the effects of flexural rigidity of the cable on the galloping of transmission lines, Luongo[10] developed the 3-DOF Curved Beam Model considering the vertical, lateral and torsion motions based on zhu[11]. This model can take into account the effect of torsion and flexural rigidity on the galloping, while the effect of the eccentricity of the iced conductor on the galloping was neglected. Recently, on the basis of Luongo[10], the 3-DOF galloping model of iced transmission lines is deduced by Yan[12] according to the curved beam theory of zhu[11] and migration coordinate system theory of Masson[13]. Then, the adjacent stiffness and insulator string 
is equivalent to a linear spring by Huo[14] on this basis, while the mass of the insulator string is neglected.

In this paper, the 3-DOF galloping models based on cable theory and curved beam theory are developed to analyze the galloping of iced transmission lines.

\section{The galloping model of iced transmission lines}

The 3-DOF model involving the vertical, horizontal and torsional motions based on cable theory is shown as following with the effects of cross-section eccentricity of the cable and the longitudinal equivalent stiffness of the adjacent considered.

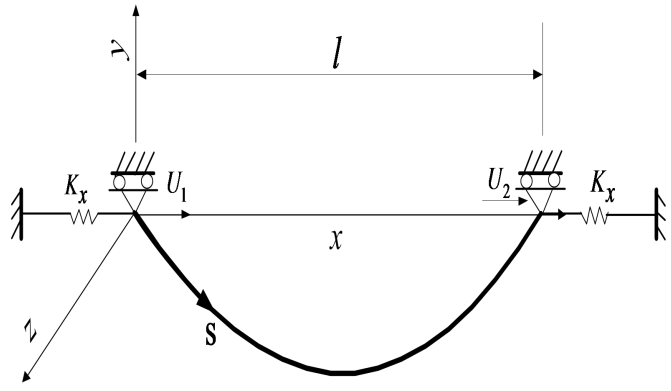

(a) space model

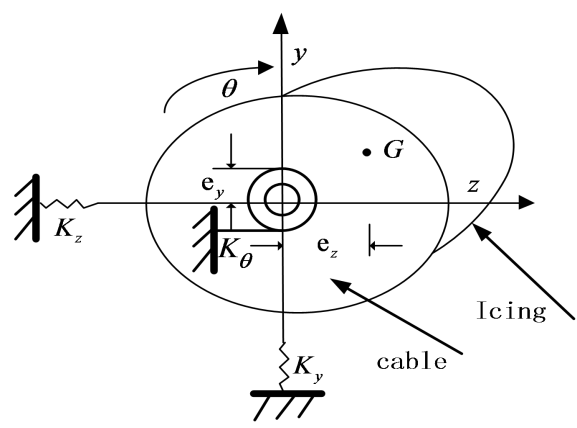

(b) cross section details

Fig.1 The iced transmission line for 3DOF galloping model based on cable theory

The 3-DOF galloping model considering the effect of cross-section eccentricity based on the curved beam theory is shown as follows:

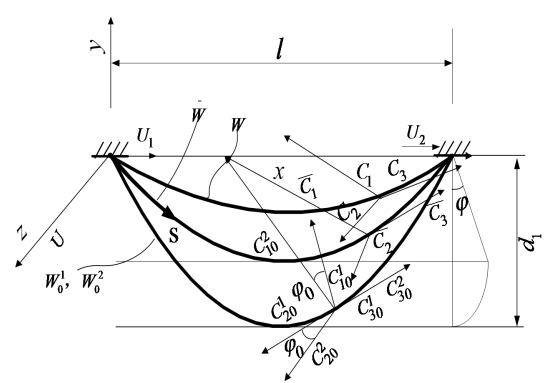

(a) space model

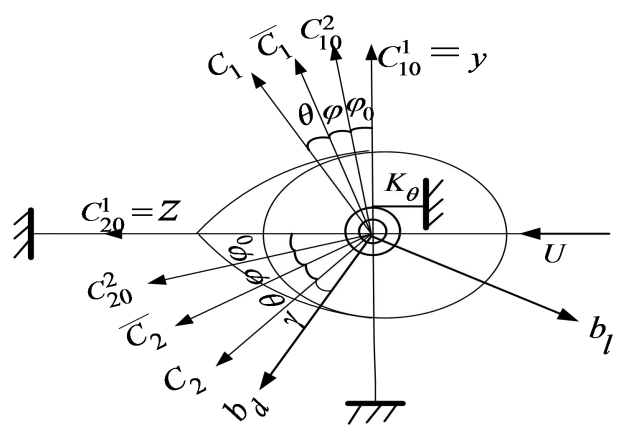

(b) cross section details

Fig. 2 The iced transmission line for 3DOF galloping model based on curved beam theory

The 3-DOF galloping model taking into account both the effect of cross-section eccentricity and the boundary stiffness based on the curved beam theory as shown in Fig.3.

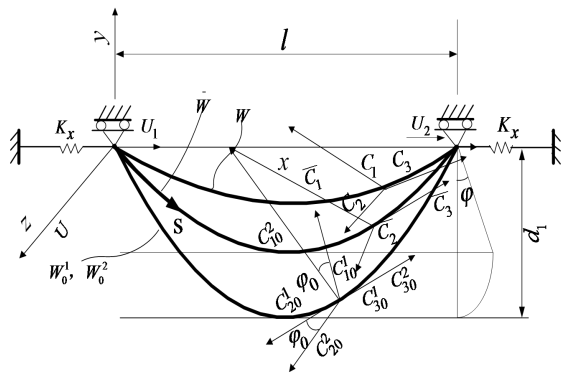

Fig.3 Iced transmission line for 3DOF galloping model considering the boundary stiffness based on curved beam theory 
The 3-DOF galloping model, in addition to the cross-section eccentricity, considering both the boundary stiffness and boundary mass based on the curved beam theory as shown in Fig.4.

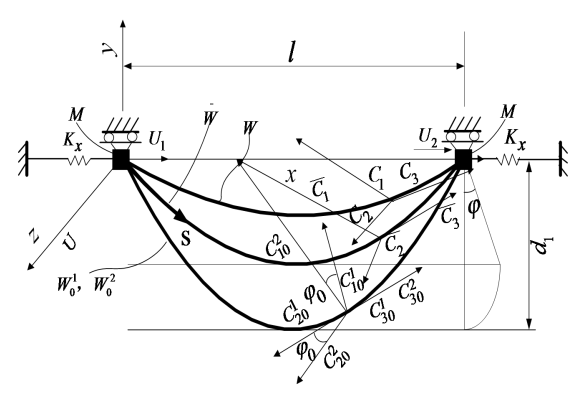

Fig.4 Iced transmission line for 3DOF galloping model considering the boundary stiffness and boundary mass based on curved beam theory

All the related details of this paper are seen in Yan[12]、Huo[12] and Li[15] .

\section{The analysis of examples}

Model validation

According to the experimental data of the D-section iced transmission lines used by $\mathrm{P} . \mathrm{Yu}[9]$, the correctness of the models adopted in this paper are verified. The cable parameters are as follows. The axial and torsional stiffness are $13.3 \times 10^{6} \mathrm{~N}$ and $101 \mathrm{Nm}^{2} \cdot \mathrm{rad}^{-1}$. The vertical and horizontal damping ratio is 0.0008 , while the torsional damping ratio is 0.0379 . Besides, the horizontal tension is $21.73 \times 10^{3} \mathrm{~N}$ and the equivalent stiffness of the support is $75.97 \mathrm{kN} / \mathrm{m}$. In addition, the adjacent span, initial eccentricity in the $\mathrm{Y}$ direction and $\mathrm{Z}$ direction are $125.9 \mathrm{~m},-0.005 \mathrm{~m}$ and $0.018 \mathrm{~m}$, respectively. Moreover, the density and the moment of inertia for the iced cable are $1.53 \mathrm{~kg} / \mathrm{m}$ and $57 \times 10^{-4} \mathrm{~kg} \cdot \mathrm{m}$, while the horizontal wind speed is $4.1 \mathrm{~m} / \mathrm{s}$.

The 3-DOF galloping model based on the cable theory (Model 1), the 3-DOF galloping model based on the curved beam theory (Model 2), the 3-DOF galloping model based on the curved beam theory only considering the boundary stiffness (Model 3) and the 3-DOF galloping model based on the curved beam theory considering both the boundary stiffness and boundary mass (Model 4) are adopted to analyzed the galloping of the iced transmission line. The displacement amplitudes calculated from the different models mentioned above are compared with those of the measured value, as shown in Table 1.

Table 1 Comparison of amplitudes for different models and experiment

\begin{tabular}{ccccc}
\hline Model & $\begin{array}{c}\text { Vertical displacement } \\
\text { amplitude } / \mathrm{m}\end{array}$ & error & $\begin{array}{c}\text { Torsional displacement } \\
\text { amplitude } / \mathrm{m}\end{array}$ & error \\
\hline Model 1 & 0.72 & $33 \%$ & 0.39 & $25 \%$ \\
Model 2 & 0.83 & $5.0 \%$ & 0.45 & $13 \%$ \\
Model 3 & 0.76 & $4.0 \%$ & 0.50 & $4.0 \%$ \\
Model 4 & 0.78 & $1.3 \%$ & 0.51 & $1.9 \%$ \\
measured & 0.79 & - & 0.52 & - \\
value & & & &
\end{tabular}

It can be seen from Table 1 that the displacement amplitude error obtained by the 3-DOF model (Model 1) based on the cable theory is very large, about 33\%. When considering the influence of the bending stiffness of the cable (Model 2), the accuracy of the galloping model is 
greatly improved, the error of the vertical displacement amplitude is about $5 \%$, while the error of the torsional displacement is about $13 \%$. When the influence of the boundary condition of the adjacent span is considered (Model 3), the vertical displacement amplitude and the torsional displacement amplitude are both reduced to $4.0 \%$. When taking into account the effects of the adjacent span stiffness and the mass of the insulator string (Model 4), the error of the vertical displacement amplitude and the torsional displacement amplitude are $1.3 \%$ and $1.9 \%$ respectively. Therefore, the 3-DOF galloping model based on the curved beam theory with the boundary stiffness and boundary mass considered can achieve high accuracy and is more suitable for practical engineering analysis.

The effect of the boundary conditions on the galloping

In order to further discuss the galloping of the iced transmission lines, the test data obtained in China Aerodynamic and Development Center are selected to analyze. The type of the transmission line used in the test is 4XLGJ-400/50. The cross-section of the iced transmission line is crescent-shaped, the diameter and the icing thickness of the cable are $27.6 \mathrm{~mm}$ and $20 \mathrm{~mm}$. The cross-sectional area of ice and the cable are A1 $=342.77 \mathrm{~mm}$ and A2 $=598.27 \mathrm{~mm}$ respectively. According to the literature ${ }^{[9]}$, the axial and torsional stiffness are $41.3 \times 10^{6} \mathrm{~N}$ and $393 \mathrm{Nm}^{2} \cdot \mathrm{rad}^{-1}$. The vertical and horizontal damping ratio is 0.0045 , while the torsional damping ratio is 0.015 . Besides, the horizontal tension is $21.73 \times 10^{3} \mathrm{~N}$ and the equivalent stiffness of the support is $75.97 \mathrm{kN} / \mathrm{m}$. In addition, the adjacent span, initial eccentricity in the $\mathrm{Y}$ direction and $\mathrm{Z}$ direction are $250 \mathrm{~m},-0.00326 \mathrm{~m}$ and $0.00326 \mathrm{~m}$, respectively. Moreover, the density and the moment of inertia for the iced cable are $1.82 \mathrm{~kg} / \mathrm{m}$ and $2.58 \times 10^{-4} \mathrm{~kg} \cdot \mathrm{m}$, and the horizontal wind speed is $6.1 \mathrm{~m} / \mathrm{s}$.

To analyze the influence of the boundary conditions on the galloping, the 3-DOF simply supported galloping model based on the cable theory, the 3-DOF rigidly fixed galloping model based on the curved beam theory and the 3-DOF galloping model considering the boundary conditions based on the curved beam theory are defined as Model 1, Model 2 and Model 3 respectively. The Mathematica procedure was used to develop and calculate the galloping models. The vertical, the horizontal and torsional displacement amplitudes of the galloping transmission lines for different models are shown in Table 2.

Table 2 Comparison of amplitudes for three galloping models

\begin{tabular}{cccc}
\hline Model & $\begin{array}{c}\text { Vertical displacement } \\
\text { amplitude } / \mathrm{m}\end{array}$ & $\begin{array}{c}\text { Horizontal displacement } \\
\text { amplitude } / \mathrm{m}\end{array}$ & $\begin{array}{c}\text { Torsional displacement } \\
\text { amplitude /rad }\end{array}$ \\
\hline Model 1 & 0.25 & 0.16 & 0.18 \\
Model 2 & 0.24 & 0.15 & 0.19 \\
Model 3 & 0.22 & 0.11 & 0.20 \\
\hline
\end{tabular}

The results of the analysis in Table 2 show that, considering the flexural rigidity, the vertical and horizontal displacement amplitude of the model decrease, the amplitude of the torsional displacement and the accuracy increases. This is due to the torsional motion shares the vertical and horizontal energy when the bending stiffness of the cable is considered. Moreover, considering the effects of the adjacent stiffness and mass of the insulator string, the amplitude of the vertical displacement and horizontal displacement are further reduced, the precision is further improved. In addition, due to the vertical, lateral and torsional directions are coupled to each other, the amplitude of the displacement increases. 


\section{Conclusions}

Based on the cable theory, the curved beam theory and Hamilton principle, the galloping model of 3-DOF iced transmission line was established. The Mathematica procedure was utilized to analyze the galloping of iced transmission lines. The results show that, considering the effects of the adjacent stiffness and mass of the insulator string, the 3-DOF galloping model based on the curved beam theory will achieve a high accuracy (the error is about $1.3 \%$ and $1.9 \%$ ). Therefore, the model can be used in the actual engineering analysis of the galloping of iced transmission line.

\section{Acknowledgements}

This work was supported by the National Natural Science Funding (China, 51478069).

\section{References}

[1] Den Hartog. Transmission line vibration due to sleet. AIEE Transmission (Part 4), 1932: 1074-1086.

[2] M.I.Kazakevich, A.G. Vasilenko. Closed Analytical Solution for Galloping Aeroelastic Self oscillations [J]. Journal of Wind Engineering and industrial Aerodynamics, 1996, 65(1-3): 353-360.

[3] O. Nigol, P. G. Buchan. Conductor galloping. 1. Den Hartog mechanism. IEEE Transactions on Power Apparatus and systems, 1981, 100(2): 699-707.

[4] O. Nigol, P. G. Buchan. Conductor galloping. 2. Torsional mechanism. IEEE Transactions on Power Apparatus and systems, 1981, 100(2): 708-720.

[5] K. F. Jones. Coupled Vertical and Horizontal Galloping[J]. Journal of Engineering Mechanics ASCE, 1992, 118(1): 92- 107.

[6]Angelo Luongo, Angelo Di Egidio, Achille Paolone. On the Proper Form of the Amplitude Modulation Equations for Resonant Systems[J]. Nonlinear Dynamics, 2002, 273:.

[7] R. D. Blevins and W. D. Iwan. The Galloping Response of a Two-Degree-of-Freedom System[J]. Apll. Mech. Trans. ASME. 1974, 96(3): 1113-1118.

[8] Y. M. Desai, A. H. Shah, N. Popplewell. Perturbation-based finite element analyses of transmission line galloping[J]. Journal of Sound and Vibration, 1996, 191(4):469-489.

[9] P.YU, Y. M. Desai, A. H. SHAH, et al. Three-Degree-of-Freedom Model for Galloping. Part I: Formulation[J]. Journal of Engineering Mechanics, 1993, 119(20):2404-2425.

[10] A. Luongo, D. Zulli, G. Piccardo. A Linear Curved-Beam Model for the Analysis of Galloping in Suspended Cables[J]. Journal of Mechanics of Materials and Structures, 2007, 2(4): 675 $-694$.

[11] Z.H. Zhu,S.A. Meguid. Vibration analysis of a new curved beam element[J]. Journal of Sound and Vibration,2008,309(1-2):86-95.

[12] Z. M. Yan, Z. T. Yan, Z. L. Li, T. Tan,. Nonlinear galloping of internally resonant iced transmission lines.considering eccentricity [J]. Journal of Sound and Vibration, 2012, 331(15): 3399-3616.

[13] J. Mason. Variational Incremental and Energy Methods in Solid Mechanics and Shell Theory[M]. Elsevier Scientific Publishing Company, 1980.

[14] T. Huo, Z. T. Yan, Z. L. Li, Z. M. Yan. A curved-beam model considering elastic boundary conditions for iced transmission line galloping $[\mathrm{J}]$. Journal of vibration and shock, 2013 , 32(21):85-91.

[15] Li Peng. Modeling and Multi-scale Method of Galloping of Iced Transmission Line Considering Boundary Condition [D]. Chongqing University, 2015. 